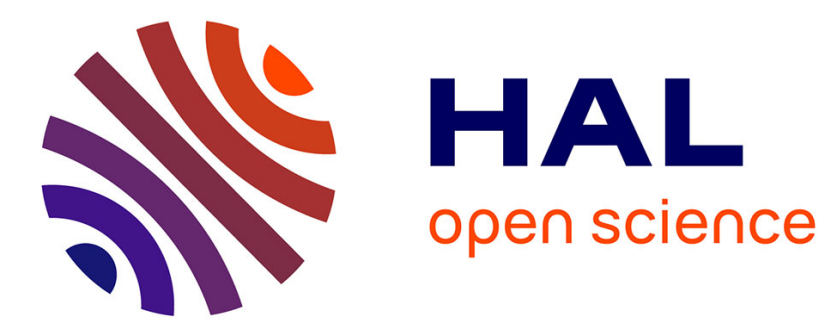

\title{
Psychosocial work factors and first depressive episode: retrospective results from the French national SIP survey
}

Isabelle Niedhammer, Jean-François Chastang

\section{- To cite this version:}

Isabelle Niedhammer, Jean-François Chastang. Psychosocial work factors and first depressive episode: retrospective results from the French national SIP survey. International Archives of Occupational and Environmental Health, 2015, 88 (7), pp.835-847. 10.1007/s00420-014-1013-y · hal-01110457

\section{HAL Id: hal-01110457 \\ https://hal.sorbonne-universite.fr/hal-01110457}

Submitted on 28 Jan 2015

HAL is a multi-disciplinary open access archive for the deposit and dissemination of scientific research documents, whether they are published or not. The documents may come from teaching and research institutions in France or abroad, or from public or private research centers.
L'archive ouverte pluridisciplinaire HAL, est destinée au dépôt et à la diffusion de documents scientifiques de niveau recherche, publiés ou non, émanant des établissements d'enseignement et de recherche français ou étrangers, des laboratoires publics ou privés. 
Psychosocial work factors and first depressive episode: retrospective results from the French national SIP survey

Isabelle Niedhammer ${ }^{1,2}$, Jean-François Chastang ${ }^{1,2}$

1 INSERM, UMR_S 1136, Pierre Louis Institute of Epidemiology and Public Health, Department of social epidemiology, F-75013, Paris, France

2 Sorbonne Universités, UPMC Univ Paris 06, UMR_S 1136, Pierre Louis Institute of Epidemiology and Public Health, Department of social epidemiology, F-75013, Paris, France

\section{Correspondence to:}

Dr. Isabelle Niedhammer

INSERM UMRS 1136 - IPLESP

Team 7 (ERES)

Faculté de Médecine Pierre et Marie Curie - pôle Saint-Antoine

27 rue de Chaligny

F-75012 Paris

France

Email: isabelle.niedhammer@inserm.fr

Word count of abstract: 250

Word count: 4712

1 appendix

42 references

5 Tables 


\section{ABSTRACT}

Objectives. The objective was to explore the associations between psychosocial work factors and first depressive episode. Additional objectives included the study of the frequency and duration of exposure, and the evaluation of the induction period between exposures and outcome and of the reversibility of the effects.

Methods. The study was based on a sample of 13648 men and women from the 2006 national representative French SIP survey. Retrospective evaluation was performed for depressive episode for the whole life history, for psychological demands, skill discretion, social support, tension with the public, reward and work-life imbalance for each job, and within each job before and after each major change, and for time-varying covariates. The outcome was the first depressive episode. Statistical analysis was performed using weighted discrete time logistic regression model.

Results. High psychological demands and low social support were risk factors of first depressive episode for both genders. The risk increased with the frequency of exposure to these factors. Associations were found with the frequency of exposure to tension with the public among women and to work-life imbalance among men. The risk increased with the duration of exposure to psychological demands and low social support for both genders, however these associations become non-significant when recent exposure was taken into account. Past exposure older than 2 years was not associated with the outcome.

Conclusion. Associations between psychosocial work factors and first depressive episode were observed, including dose-response associations. However, after removal of the exposure, the risk may be reduced after two years.

Keywords: psychosocial work factors; depression; retrospective data 


\section{Introduction}

Mental health at work is a crucial issue in occupational health because of its high costs and its heavy impact on absenteeism, presenteeism, and other work-related outcomes such as reduced work performance and turnover (Birnbaum, Kessler, Kelley, Ben-Hamadi, Joish \& Greenberg, 2010; Kessler, Akiskal, Ames, Birnbaum, Greenberg, RM et al. 2006). Identifying occupational risk factors for mental disorders appears therefore crucial. A number of psychosocial work factors have been shown to be associated with common mental disorders in reviews or meta-analysis of prospective studies (Bonde, 2008; Netterstrom, Conrad, Bech, Fink, Olsen, Rugulies et al. 2008; Siegrist, 2008; Stansfeld \& Candy, 2006), these studies being often limited to well-known factors such as those related to the job strain and effort-reward imbalance models (Karasek, Brisson, Kawakami, Houtman, Bongers \& Amick, 1998; Siegrist, Starke, Chandola, Godin, Marmot, Niedhammer et al. 2004). Thus, these reviews and meta-analysis demonstrated that the risk of mental disorders, especially depression, may increase with high psychological demands, low decision latitude (comprising low skill discretion and low decision authority), the combination of high demands and low latitude, and low social support (job strain model). They also reported that this risk may increase with the combination of high effort and low reward (effort-reward imbalance model). The literature appears more seldom for other factors not covered by these two models, and there may be a need to explore the psychosocial work environment more widely (Netterstrom et al., 2008).

In addition, authors underlined the need to assess in more detail the duration and frequency/intensity of exposure to psychosocial work factors in association with mental disorders (Netterstrom et al., 2008). Indeed, this point may be crucial in the demonstration of causal associations and models of the putative chains of causation have been elaborated such as the allostatic load model that conceptualises the development of chronic disease within a framework of physiological 'wear and tear' resulting from the accumulation of stressful exposures, including occupational exposures at the workplace (Mauss, Li, Schmidt, Angerer \& Jarczok, 2014). Furthermore, almost no study examined cumulative working life course exposure to psychosocial work factors, and these very rare studies focused on mortality and cardiovascular diseases. These studies used an indirect evaluation of psychosocial work factors through job-exposure matrix or other imputation methods, whose limitations are wellknown (unmeasured within-occupation variability in exposures, evaluation of exposure 
depending on the level of precision of the occupation classification used, etc.) (Amick, III, McDonough, Chang, Rogers, Pieper \& Duncan, 2002; Johnson, Stewart, Hall, Fredlund \& Theorell, 1996; Theorell, Tsutsumi, Hallquist, Reuterwall, Hogstedt, Fredlund et al. 1998). Although the collection of lifetime exposures may be highly desirable, such information may be difficult to collect. Whereas cross-sectional studies provide information about exposures and outcome at a given time, prospective studies examine in general the association between exposures at baseline and the occurrence of outcome during follow-up. Both designs have their own limitations and generally do not include lifetime or life course exposures, leading to misclassification that, if non differential, may bias the results towards the null hypothesis. Retrospective collection of data may thus constitute an interesting perspective that may be seen as complementary to data provided by job-exposure matrix. Another important question may be the induction period between exposure to psychosocial work factors and mental disorders. In a previous study, we found that past exposure to bullying within the last 12 months was associated with depressive symptoms, but with a lower magnitude than current exposure (Niedhammer, David, Degioanni \& 143 occupational physicians, 2006). After removal of exposure, it may be assumed that the older the past exposure, the lower the increase of risk of disease, but no precise information is available on this point in the literature to date, in particular information is not available on whether the risk returns to baseline and if yes, how long this process may take.

The main objective of the study was to explore the associations between the exposure to psychosocial work factors and the first episode of depression. Three additional objectives were: the study of the associations between (i) the frequency and (ii) duration of exposure to these factors and first depressive episode, and (iii) the evaluation of the induction period between exposures and outcome and of the reversibility of the effects, i.e. the study of the association between the year of last exposure and outcome.

\section{Methods}

\section{Population}

The study was based on the data from the national representative SIP (Santé et Itinéraire Professionnel) survey, conducted by the French Ministry of Labour (DARES), the French Ministry of Health (DRESS), the French Centre for Employment Studies (CEE) and the French National Institute for Statistics and Economic Studies (INSEE). The main objective of 
the survey was to provide information about the occupational determinants of health in the national French population (Coutrot, Rouxel, Bahu, Herbet \& Mermilliod, 2010). In 2006, households were randomly selected from the 1999 census, that was updated for new housings, and one individual aged between 20 and 74 years was randomly selected to be interviewed in each household. Consequently, the survey included a sample of the general population of 13648 participants (6195 men and 7453 women) aged 20-74 years in 2006. The response rate was $76 \%$. Previous studies by our team have already been published using these data (Malard, Chastang \& Niedhammer, 2014; Murcia, Chastang \& Niedhammer, 2013).

Data were collected face to face by trained interviewers at respondent's home. The collection of data was based on Computer-Assisted Personal Interviewing (CAPI). The interview included a time ruler and a questionnaire. The people were asked about childhood until the end of education, occupational history and health status using a life course perspective. The time ruler was used to help the people to remember, and to make the collection of data complete and consistent.

\section{Psychosocial work factors}

Using the time ruler and from the entry to working life, all the jobs that were held in the past were collected. The collection of data was done on a yearly basis. Psychosocial work factors were collected retrospectively for each job held and, in a given job, for each period before and after major changes (that were major changes in job content or working conditions). Psychosocial work factors included 6 factors that were: psychological demands, skill discretion, social support, reward, tensions with the public and work-life imbalance (Appendix). Response categories were never, rarely, often and always.

Four types of analyses were performed. In the first analysis, the items were dichotomized at the median of the distribution in the total sample; these binary variables were used to maximize the statistical power. In the second analysis, the frequency of exposure was studied using the 4 initial response categories of the variables. In the third analysis, the duration of exposure to psychosocial work factors was measured for each gender and age group. Firstly, the mean duration of exposure to each factor in years was calculated for each gender*age group and secondly, the positive or negative deviation in years from the mean was calculated for each person within the same group. This continuous variable was used in the models to measure the increase of risk of first depressive episode associated with one year of exposure 
in excess. To evaluate the relative importance of the duration of exposure and exposure at year i, we further adjusted the models for exposure at year i. Finally, in the fourth analysis, variables were constructed to study the induction period between exposure and outcome. The objective of this analysis was to study the association between the year of the last exposure and first depressive episode. The exposures were measured by the year of the last exposure using 3 groups: never exposed with the last three years (i.e. at year i, i-1 and i-2), non-exposed at year i but exposed at year i-1 or i-2, and exposed at year i.

\section{First depressive episode}

Using the time ruler, the survey included the collection of all major diseases that occurred during life and that were self-reported by the participants retrospectively and at the time of the survey in 2006. The objective was to collect serious diseases that had an impact on people life. To help people to remember, a list of major diseases was presented -that was close to the main groups of the International Classification of Diseases (ICD-10)-, but all diseases reported spontaneously were also collected. Diseases were coded using the ICD-10. For each depressive episode, coded F32, that occurred during life, the year of occurrence and the duration of the episode were collected. The first depressive episode was used as the outcome of the study.

\section{Covariates}

Covariates were age (in 10-y age groups), marital status (living alone or not), stressful life events during childhood (i.e. before 18) and during adulthood (Appendix), and occupation coded using the French classification of occupation that is close to the international classification of occupation (ISCO). Using the time ruler, all the changes in marital status and occupation, and the occurrence of life events were collected for the whole life history. Additional covariates were taken into account for the study of duration of exposure: the number of years spent unemployed or non-working.

\section{Statistical methods}

Weights were calculated using a calibration on margins (calibration variables were: age, gender, employment status, occupational groups, economic activities, urbanisation level and number of people in household) and inverse probability weighting to provide estimates representative of the population in 2006 (Coutrot et al., 2010). All analyses were conducted 
using weighted data to control for a potential bias related to non-response and to provide representative results for the national population.

A description of the study sample was done using persons-years for all the variables used. A comparison between genders was also performed to study the differences in the distribution of the variables using the data of 2006 or the most recent data for those who were not working in 2006 using Rao-Scott Chi-Square test.

The study was based on person-year records and only person-year records related to age 1864 and working periods (for some analyses) were retained. People contributed to person-year records from the year they began to work. Person-year records ended when the first depressive episode occurred, or by the year of interview in 2006, or by the year people stopped working for more than one year and never worked after that, whichever came first. The association between psychosocial work factors at year i (or before) and first depressive episode one year later (year $\mathrm{i}+1$ ) was studied using a weighted discrete time logistic regression model (Allison, 1982). Covariates were taken into account at year $\mathrm{i}$ for age, occupation, marital status and stressful life events during childhood and adulthood. All variables were time-varying except stressful life events during childhood (before 18). Two models were performed, the first one including each psychosocial work factor separately with adjustment for covariates and the second one including all psychosocial work factors together with adjustment for covariates. These two models were used for the binary, frequency, duration and last exposure variables of psychosocial work factors. Trend tests were also performed to study the dose-response associations between frequency of exposure and first depressive episode.

The sample size varied according to the four different analyses because of the variables used. In the first and second analyses, we used all working persons-years, consequently nonworking persons-years at year i were not included. In the third analysis, we used all personsyears, both working and non-working, but as we calculated the duration of exposure, the data had to be available not only at year i but also at all years before i. In the fourth analysis, we used all working persons-years and the data had to be available for years i, i-1 and i-2.

Interaction terms between high psychological demands and low skill discretion were examined to test Karasek's hypothesis of job strain. Interaction terms were also tested 
between each factor and gender to test whether the association with the outcome was different according to gender among the whole sample.

Statistical analysis was done using SAS, and for men and women separately.

\section{Results}

The study sample included 13648 people, 6195 men and 7453 women, and a total of 396499 persons-years, 183265 men-years and 213234 women-years, i.e. a mean duration per person of 29.13 years (29.61 years for men and 28.73 years for women). A total of 158 first depressive episodes among men and of 358 first episodes among women occurred.

Table 1 presents the description of the study sample for all variables in terms of personsyears. Significant differences were observed between genders when the variables were compared for the year 2006 or the most recent data (not shown). Men were more likely to be exposed to psychological demands than women, and women were more likely to be exposed to low skill discretion and low social support (using the frequency variable) than men. Gender differences were also found for covariates. Women were more likely to be exposed to life events than men. Women were more likely to be clerks/service workers and men professionals/managers and manual workers.

Table 2 (top of the Table) presents the associations between psychosocial work factors (binary variables) and first depressive episode with adjustment for covariates, each factor being studied separately. All psychosocial work factors were associated with first depressive episode except skill discretion and tension with the public among men. An interaction term was observed between low social support and gender suggesting that the association with the outcome was stronger for men than for women. After inclusion of all psychosocial work factors together in the same models (Table 2, bottom of the Table), psychological demands and low social support were found to be risk factors for both genders. No significant interaction term was observed between psychological demands and skill discretion.

The analysis of the associations between the frequency of exposure to psychosocial work factors and first depressive episode displayed significant trend tests suggesting that the risk of first episode increased with the frequency of exposure to all factors, when each factor was 
studied separately (Table 3). When studied together (Table 3), the risk of first depressive episode increased with the frequency of exposure to psychological demands and low social support for both genders, with the frequency of exposure to tension with the public among women and with the frequency of exposure to work-life imbalance among men.

The duration of exposure to psychosocial work factors increased the risk of first depressive episode for both genders and for all factors except skill discretion when the factors were studied separately (Table 4). When the factors were studied simultaneously, the duration of exposure to high psychological demands and low social support increased the risk of first depressive episode for both genders. However, the associations between the duration of exposure and first depressive episode become non-significant when the exposure at year i was included in the models, meaning that exposure at year i may be more important than cumulative duration of exposure (not shown).

Exposure at year i was associated with first depressive episode for all factors except work-life imbalance for both genders and skill discretion and tension with the public for men when each factor was studied separately (Table 5). Exposure at year i-1 or i-2 was not significant, but as the statistical power was low because of low sample sizes, it may be noticed that the oddsratios values were mostly higher than 1 . When all factors were studied simultaneously (Table 5), exposure at year i was significantly associated with the outcome for psychological demands and social support for both genders and reward for women. The odds-ratios associated with exposure at year i-1 or i- 2 were in general higher than one but non-significant.

Regarding the associations between covariates and first depressive episode (not shown), older age was a risk factor for both genders. Living alone was associated with first depressive episode for both genders. Stressful life events during childhood increased the risk of first depressive episode among women, and life events during adulthood increased the risk among men. Occupation was associated with first depressive episode among women, managers/professionals being at lower risk. Unemployment and other non-working periods were included as additional covariates in the study of the duration of exposure. Unemployment was associated with first depressive episode, but other non-working periods were not.

\section{Discussion}




\section{Main results}

In the analyses exploring each psychosocial work factor separately, almost all factors were associated with first depressive episode for both genders. The study of all factors together showed that high psychological demands and poor social support for both genders were risk factors of first depressive episode. The risk increased with the frequency of exposure to psychosocial work factors when each factor was studied separately, and with the frequency of exposure to high psychological demands and low social support for both genders, with the frequency of exposure to tension with the public among women, and with the frequency of exposure to work-life imbalance among men, when the factors were studied simultaneously. The duration of exposure to psychosocial work factors (except skill discretion) increased the risk of first depressive episode when each factor was studied separately, and the duration of exposure to psychological demands and low social support increased the risk for both genders, when they were studied simultaneously. Recent exposure may be more important than the duration of exposure and past exposure. Past exposure older than 2 years was not found to be associated with the outcome.

\section{Strengths and limitations of the study}

The strengths of the study may be underlined. The study was based on a large national representative sample of the French population (i.e. not a specific or selected population of workers) with a satisfactory response rate (76\%). As weighted data were used in all analyses, we controlled for a potential bias related to non-response and the results may be generalized to the whole national population. Men and women were examined separately something that may be considered fundamental given the strong differences between genders in terms of occupation, working conditions, including psychosocial work factors, covariates and depressive episode (Niedhammer, Saurel-Cubizolles, Piciotti \& Bonenfant, 2000). However, almost all the associations between psychosocial work factors and first depressive episode were similar for men and women. Life course retrospective data for both exposures and outcome and their temporal sequences were available. Retrospective data covered a large period of time from entry into working life with a mean duration of more than 29 years. The study explored the incidence of depressive episode (in other words, first episode), something that has been rare in the literature. The temporal sequence of psychosocial work factors and first depressive episode was clearly defined, as the association between exposures to psychosocial work factors and outcome one year later was studied. No selection bias may be 
suspected as all working periods before the incidence of depressive episode were considered. We were also able to take the information about non-working periods into account in a sensitivity analysis, and the results were unchanged. Exposure to psychosocial work factors was considered for each past job, and even, for a given job, before and after major changes, reducing the risk of misclassification that is common in studies evaluating one measure of exposure only. Psychosocial work factors were examined including both classical concepts (from the job strain and effort-reward imbalance models) as well as two emergent concepts (tension with the public and work-life imbalance). We examined both frequency and duration of exposure, both variables bringing elements on dose-response associations in accordance with possible biological mechanisms such as the allostatic load model (Sluiter, Frings-Dresen, van der Beek, Meijman \& Heisterkamp, 2000). We were also able to bring elements on the induction period. Major covariates, considered as well-known risk factors of depression, were taken into account, and their results were consistent with the literature. A sensitivity analysis was also performed using chronic diseases as an additional criterion for right-censoring and provided similar results. Two types of models were performed allowing us to study the associations between psychosocial work factors and first depressive episode using two approaches, the first one exploring each factor separately, and the second one exploring all factors together, i.e. independently of each other. The second approach may be considered conservative and lead to overadjustment as there may be complex interrelations between factors and factors may be causes or consequences of other factors (Rugulies, Aust \& Pejtersen, 2010).

Some limitations deserve to be mentioned. The data were retrospective, and it may be difficult to conclude to causal associations. A recall bias may be present but its impact on the results may be low (a sensitivity analysis confirmed the robustness of the results after inclusion of a variable taking the time interval between first depressive episode and time of interview in 2006 into account). Retrospective collection of exposure to psychosocial work factors may not be sensitive enough to capture changes and may explain why the changes in the exposures were seldom in our study. Rare studies showed that collecting retrospective data about psychosocial work conditions may have a moderate quality, but underlined that it may be valuable for measuring the health effects of historical job characteristics, which often change over time (Koster, Alfredsson, Michelsen, Vingard \& Kilbom, 1999; Landsbergis, Schnall, Pickering \& Schwartz, 2002). No information from registers or other sources was available for this survey to help and control the retrospective data given by the respondents. A reporting 
bias may be suspected as both exposure to psychosocial work factors and depressive episode were self-reported at the time of the survey in 2006. Consequently, as many other studies before, our study was not able to overcome the methodological problem of reporting bias (Bonde, 2008). Furthermore, we may think that the perception of psychosocial work factors and mental disorders may have changed within the last decades making the comparability difficult over time. Psychosocial work factors were not measured using validated questionnaires, leading to potential imprecision in the variables used. Furthermore, our proxies were based on one single item each. However, other authors underlined the interest and validity to construct proxies (Karasek, Choi, Ostergren, Ferrario \& De, 2007). Some psychosocial work factors were neglected as they were not available in the survey, and may be important in the association with depression, such as job insecurity (Stansfeld \& Candy, 2006). A lack of statistical power was observed when we studied the induction period, as the changes in psychosocial work factors were not frequent (psychosocial work exposures did not change within the last 3 years for around $80 \%$ of the sample studied). Consequently, our results for past exposures should be considered with caution, and the conclusion may be that past exposure had a lower impact on first depressive episode than recent exposure. Because of multiple testing, some results may be due to chance. However, some authors suggested that controlling for multiple testing may not be necessary in the case of an exploratory study (Bender \& Lange, 2001). Depressive episode was self-reported and coded using the ICD-10 but not based on a structured diagnostic interview.

\section{Comparison with the literature}

Our results are in accordance with the literature on the association between the factors of the job strain model and mental disorders, especially depression. In agreement with reviews and meta-analysis (Bonde, 2008; Netterstrom et al., 2008; Stansfeld \& Candy, 2006), high psychological demands and low social support were risk factors of first depressive episode. The results of the literature are seldom regarding the presence of an interaction between high psychological demands and low decision latitude in association with mental disorders. Our results showed that there was no interaction between psychological demands and skill discretion. One previous study found an interaction between psychological demands and decision latitude in association with depression among men (Murcia et al., 2013). In our study, the associations of high psychological demands and low social support with first depressive episode were still significant even after adjustment for all psychosocial work factors together. Reward, measured as a proxy for the dimension of effort-reward imbalance 
model, was found to be associated with first depressive episode in the first model (each factor studied separately). Our previous study using the 2006 cross-sectional data of the SIP survey and a diagnostic interview confirmed this result (Murcia et al., 2013). Another cross-sectional study also reported a significant association between reward and psychiatric symptoms among men (Niedhammer, Chastang, David, Barouhiel \& Barrandon, 2006). Work-life imbalance was found to be associated with first depressive episode in our first model, confirming previous findings showing an association between this factor and depression (Wang, Patten, Currie, Sareen \& Schmitz, 2012; Wang, Smailes, Sareen, Schmitz, Fick \& Patten, 2012; Wang, Lesage, Schmitz \& Drapeau, 2008). Tension with the public was found to be a risk factor among women in our study. This result is in line with previous studies showing an association of person-related work or emotional demands with depressive disorders (Kim, Noh \& Muntaner, 2013; Madsen, Diderichsen, Burr \& Rugulies, 2010). Furthermore, other studies reported associations between workplace violence and depression or depressive symptoms (Kivimäki, Virtanen, Vartia, Elovainio, Vahtera \& Keltikangas-Jarvinen, 2003; Niedhammer et al., 2006). In addition, a previous study demonstrated that the frequency of exposure to workplace bullying increased the risk of depressive symptoms (Niedhammer et al., 2006). The present study is consistent with these previous results and suggests that the frequency of exposure to other psychosocial work factors may increase the risk of first depressive episode.

Although studies using retrospective data are missing in the literature, a small number of prospective studies were based on 2 or 3 measurements of exposure to psychosocial work factors. These studies were able to explore the cumulative or repeated exposure to psychosocial work factors or the changes in the exposures (increase, no change, and decrease in the exposure). Only a few of them focused on mental health outcomes, still more rarely on depression, and explored the factors of the job strain model (Bourbonnais, Comeau \& Vezina, 1999; de Lange, Taris, Kompier, Houtman \& Bongers, 2004; de Lange, Taris, Kompier, Houtman \& Bongers, 2002; Dormann \& Zapf, 2002; Godin, Kittel, Coppieters \& Siegrist, 2005; Smith \& Bielecky, 2012; Stansfeld, Fuhrer, Shipley \& Marmot, 1999; Stansfeld, Shipley, Head \& Fuhrer, 2012; Strazdins, D'Souza, Clements, Broom, Rodgers \& Berry, 2011; Wang, Schmitz, Dewa \& Stansfeld, 2009). A study showed that a cumulative job strain exposure and a change from non-exposed to exposed were associated with psychological symptoms (Bourbonnais et al., 1999). Two other studies found similar results using a diagnostic interview to measure depression (Stansfeld et al., 2012; Wang et al., 2009). A 
study found that deterioration in job demands, control and insecurity was associated with deterioration in symptoms of depression and anxiety (Strazdins et al., 2011). A study reported that negative changes in decision authority, psychological demands, and social support predicted psychiatric disorder especially among men (Stansfeld et al., 1999). Another study underlined the importance of the increase in psychological demands in predicting depression measured using a diagnostic interview (Smith \& Bielecky, 2012). Regarding effort-reward imbalance model, two studies showed that cumulative exposure to effort-reward imbalance was associated with elevated risk of five indicators of poor mental health (Godin et al., 2005) and negative changes in effort-reward imbalance were associated with depressive symptoms (Li, Weigl, Glaser, Petru, Siegrist \& Angerer, 2013).

Our results regarding the duration of exposure may be seen as consistent with the literature for psychological demands and social support for the models fully adjusted and also for reward for the models studying each factor separately. For the other factors, the literature is sparse. The risk of first depressive episode may increase with the duration of exposure to these factors, but recent exposure may be more important than cumulative duration. Our findings also suggest that the strongest associations may be found for recent exposure and that the associations may be of smaller magnitude when the exposure is older.

\section{Conclusion}

This retrospective study reported that factors of the job strain and effort-reward imbalance models as well as tension with the public and work-life imbalance may be risk factors of first depressive episode. Dose-response associations were observed for both the frequency and duration of exposure to psychosocial work factors. The induction period was also explored and the results suggest that the effects of psychosocial work factors on mental health may be reduced after the removal of exposure two years later. This point, that may be particularly useful, should be confirmed by other studies, especially prospective studies. 


\section{Acknowledgements}

The authors thank the members of the DARES, DREES, CEE and INSEE, and all the people who participated to the SIP survey and made this study possible.

\section{Funding}

French ministry of labour (DARES, grant no 2200727156).

\section{Conflict of interest}

The authors declare that they have no conflict of interest. 
Appendix List of the items for the variables used in the study

\section{$\underline{\text { Psychosocial work factors }}$}

- psychological demands (1 item: work under pressure)

- skill discretion (1 item: use of skills)

- social support (1 item: good relationships with colleagues)

- reward (1 item: fair feedback on the work done)

- tensions with the public (1 item: tensions with clients, users, patients, students, etc.)

- work-life imbalance (1 item: work in line with family life)

\section{$\underline{\text { Stressful life events }}$}

- stressful life events during childhood, i.e. before 18 (12 items: disability, long illness, serious health problems of close family member, death of close family member, long separation of close family member, family conflicts, physical, psychological and sexual abuse, material deprivation, repeated conflicts or violence at school or in neighbourhood, interruption of apprenticeship or professional training for health reasons, war or other serious events)

- stressful life events during adulthood (10 items: separation/divorce, death of close family member, care of close family member with health problems or disability, violence, conflict, strong deterioration in living conditions, social/political event, war or other serious events) 


\section{References}

Allison,P.D. (1982). Discrete-Time Methods for the Analysis of Event Histories. Sociological Methodology, 13 61-98.

Amick,B.C., III, McDonough,P., Chang,H., Rogers,W.H., Pieper,C.F., \& Duncan,G. (2002). Relationship between all-cause mortality and cumulative working life course psychosocial and physical exposures in the United States labor market from 1968 to 1992. Psychosom.Med., 64(3), 370-381.

Bender,R., \& Lange,S. (2001). Adjusting for multiple testing--when and how? $J$ Clin.Epidemiol., 54(4), 343-349.

Birnbaum,H.G., Kessler,R.C., Kelley,D., Ben-Hamadi,R., Joish,V.N., \& Greenberg,P.E. (2010). Employer burden of mild, moderate, and severe major depressive disorder: mental health services utilization and costs, and work performance. Depress.Anxiety., 27(1), 78-89.

Bonde,J.P. (2008). Psychosocial factors at work and risk of depression: a systematic review of the epidemiological evidence. Occup.Environ.Med., 65(7), 438-445.

Bourbonnais,R., Comeau,M., \& Vezina,M. (1999). Job strain and evolution of mental health among nurses. J.Occup.Health Psychol., 4(2), 95-107.

Coutrot,T., Rouxel,C., Bahu,M., Herbet,J.B., \& Mermilliod,C. (2010). Parcours professionnel et état de santé. Premières Informations et Premières Synthèses, 1.

de Lange,A.H., Taris,T.W., Kompier,M.A., Houtman,I., \& Bongers,P.M. (2004). The relationships between work characteristics and mental health: examining normal, reversed and reciprocal relationships in a 4-wave study. Work \& Stress, 18(2), 149-166.

de Lange,A.H., Taris,T.W., Kompier,M.A., Houtman,I.L., \& Bongers,P.M. (2002). Effects of stable and changing demand-control histories on worker health. Scand.J.Work Environ.Health, 28(2), 94-108.

Dormann,C., \& Zapf,D. (2002). Social stressors at work, irritation, and depressive symptoms: Accounting for unmeasured third variables in a multi-wave study. J.Occup Organizational Psychology, 75 33-58.

Godin,I., Kittel,F., Coppieters,Y., \& Siegrist,J. (2005). A prospective study of cumulative job stress in relation to mental health. BMC.Public Health, 567.

Johnson,J.V., Stewart,W., Hall,E.M., Fredlund,P., \& Theorell,T. (1996). Long-term psychosocial work environment and cardiovascular mortality among Swedish men. Am.J.Public Health, 86(3), 324-331.

Karasek,R., Brisson,C., Kawakami,N., Houtman,I., Bongers,P., \& Amick,B. (1998). The Job Content Questionnaire (JCQ): an instrument for internationally comparative assessments of psychosocial job characteristics. J.Occup.Health Psychol., 3(4), 322-355.

Karasek,R., Choi,B., Ostergren,P.O., Ferrario,M., \& De,S.P. (2007). Testing two methods to create comparable scale scores between the Job Content Questionnaire (JCQ) and JCQ-like questionnaires in the European JACE Study. Int.J Behav.Med, 14(4), 189-201. 
Kessler,R.C., Akiskal,H.S., Ames,M., Birnbaum,H., Greenberg,P., RM,A., Jin,R., Merikangas,K.R., Simon,G.E., \& Wang,P.S. (2006). Prevalence and effects of mood disorders on work performance in a nationally representative sample of U.S. workers. Am.J Psychiatry, 163(9), 1561-1568.

Kim,I.H., Noh,S., \& Muntaner,C. (2013). Emotional demands and the risks of depression among homecare workers in the USA. Int Arch Occup Environ Health, 86(6), 635-644.

Kivimäki,M., Virtanen,M., Vartia,M., Elovainio,M., Vahtera,J., \& Keltikangas-Jarvinen,L. (2003). Workplace bullying and the risk of cardiovascular disease and depression. Occup.Environ.Med., 60(10), 779-783.

Koster,M., Alfredsson,L., Michelsen,H., Vingard,E., \& Kilbom,A. (1999). Retrospective versus original information on physical and psychosocial exposure at work. Scand $J$ Work Environ.Health, 25(5), 410-414.

Landsbergis,P.A., Schnall,P.L., Pickering,T.G., \& Schwartz,J.E. (2002). Validity and reliability of a work history questionnaire derived from the Job Content Questionnaire. J.Occup.Environ.Med., 44(11), 1037-1047.

Li,J., Weigl,M., Glaser,J., Petru,R., Siegrist,J., \& Angerer,P. (2013). Changes in psychosocial work environment and depressive symptoms: a prospective study in junior physicians. Am.J Ind.Med, 56(12), 1414-1422.

Madsen,I.E., Diderichsen,F., Burr,H., \& Rugulies,R. (2010). Person-related work and incident use of antidepressants: relations and mediating factors from the Danish work environment cohort study. Scand J Work Environ.Health, 36(6), 435-444.

Malard,L., Chastang,J.-F., \& Niedhammer,I. (2014). Changes in psychosocial work factors in the French working population between 2006 and 2010. Int Arch Occup Environ Health, (in press).

Mauss,D., Li,J., Schmidt,B., Angerer,P., \& Jarczok,M.N. (2014). Measuring Allostatic Load in the Workforce-A Systematic Review. Ind.Health.

Murcia,M., Chastang,J.F., \& Niedhammer,I. (2013). Psychosocial work factors, major depressive and generalised anxiety disorders: Results from the French national SIP study. $J$ Affect.Disord., 146(3), 319-327.

Netterstrom,B., Conrad,N., Bech,P., Fink,P., Olsen,O., Rugulies,R., \& Stansfeld,S. (2008). The relation between work-related psychosocial factors and the development of depression. Epidemiol.Rev., 30 118-132.

Niedhammer,I., Chastang,J.F., David,S., Barouhiel,L., \& Barrandon,G. (2006). Psychosocial work environment and mental health: Job-strain and effort-reward imbalance models in a context of major organizational changes. Int.J Occup.Environ.Health, 12(2), 111-119.

Niedhammer,I., David,S., Degioanni,S., \& 143 occupational physicians (2006). Association between workplace bullying and depressive symptoms in the French working population. J.Psychosom.Res., 61(2), 251-259. 
Niedhammer,I., Saurel-Cubizolles,M.J., Piciotti,M., \& Bonenfant,S. (2000). How is sex considered in recent epidemiological publications on occupational risks? Occup Environ Med, 57(8), 521-527.

Rugulies,R., Aust,B., \& Pejtersen,J.H. (2010). Do psychosocial work environment factors measured with scales from the Copenhagen Psychosocial Questionnaire predict register-based sickness absence of 3 weeks or more in Denmark? Scand J Public Health, 38(3 Suppl), 42-50.

Siegrist,J. (2008). Chronic psychosocial stress at work and risk of depression: evidence from prospective studies. Eur.Arch.Psychiatry Clin.Neurosci., 258 Suppl 5 115-119.

Siegrist,J., Starke,D., Chandola,T., Godin,I., Marmot,M., Niedhammer,I., \& Peter,R. (2004). The measurement of effort-reward imbalance at work: European comparisons. Soc.Sci.Med., 58(8), 1483-1499.

Sluiter,J.K., Frings-Dresen,M.H., van der Beek,A.J., Meijman,T.F., \& Heisterkamp,S.H. (2000). Neuroendocrine reactivity and recovery from work with different physical and mental demands. Scand.J.Work Environ.Health, 26(4), 306-316.

Smith,P.M., \& Bielecky,A. (2012). The impact of changes in job strain and its components on the risk of depression. Am.J Public Health, 102(2), 352-358.

Stansfeld,S., \& Candy,B. (2006). Psychosocial work environment and mental health--a metaanalytic review. Scand.J Work Environ.Health, 32(6), 443-462.

Stansfeld,S.A., Fuhrer,R., Shipley,M.J., \& Marmot,M.G. (1999). Work characteristics predict psychiatric disorder: prospective results from the Whitehall II Study. Occup.Environ.Med., 56(5), 302-307.

Stansfeld,S.A., Shipley,M.J., Head,J., \& Fuhrer,R. (2012). Repeated job strain and the risk of depression: longitudinal analyses from the Whitehall II study. Am.J Public Health, 102(12), 2360-2366.

Strazdins,L., D'Souza,R.M., Clements,M., Broom,D.H., Rodgers,B., \& Berry,H.L. (2011). Could better jobs improve mental health? A prospective study of change in work conditions and mental health in mid-aged adults. J.Epidemiol.Community Health, 65(6), 529-534.

Theorell,T., Tsutsumi,A., Hallquist,J., Reuterwall,C., Hogstedt,C., Fredlund,P., Emlund,N., \& Johnson,J.V. (1998). Decision latitude, job strain, and myocardial infarction: a study of working men in Stockholm. The SHEEP Study Group. Stockholm Heart epidemiology Program. Am.J.Public Health, 88(3), 382-388.

Wang,J., Patten,S.B., Currie,S., Sareen,J., \& Schmitz,N. (2012). A population-based longitudinal study on work environmental factors and the risk of major depressive disorder. Am.J.Epidemiol., 176(1), 52-59.

Wang,J., Schmitz,N., Dewa,C., \& Stansfeld,S. (2009). Changes in perceived job strain and the risk of major depression: results from a population-based longitudinal study. Am.J Epidemiol., 169(9), 1085-1091. 
Wang,J., Smailes,E., Sareen,J., Schmitz,N., Fick,G., \& Patten,S. (2012). Three job-related stress models and depression: a population-based study. Soc.Psychiatry Psychiatr.Epidemiol., 47(2), 185-193.

Wang,J.L., Lesage,A., Schmitz,N., \& Drapeau,A. (2008). The relationship between work stress and mental disorders in men and women: findings from a population-based study. $J$ Epidemiol.Community Health, 62(1), 42-47. 
Table 1 Description of the sample studied for psychosocial work factors and covariates (in persons-years)

\begin{tabular}{|c|c|c|c|c|}
\hline & $\begin{array}{c}\text { Men } \\
\mathrm{N}\end{array}$ & $\begin{array}{c}\mathrm{N}=152600 \\
\text { persons-years } \\
\%\end{array}$ & $\begin{array}{c}\text { Women } \\
\mathrm{N}\end{array}$ & $\begin{array}{c}\mathrm{N}=138746 \\
\text { persons-years } \\
\%\end{array}$ \\
\hline \multicolumn{5}{|c|}{$\begin{array}{l}\text { PSYCHOSOCIAL WORK FACTORS } \\
\text { (binary variables) }\end{array}$} \\
\hline \multicolumn{5}{|c|}{ Psychological demands } \\
\hline Low & 74555 & 48.86 & 71844 & 51.78 \\
\hline High & 78045 & 51.14 & 66902 & 48.22 \\
\hline \multicolumn{5}{|c|}{ Skill discretion } \\
\hline High & 103407 & 67.76 & 87985 & 63.41 \\
\hline Low & 49193 & 32.24 & 50761 & 36.59 \\
\hline \multicolumn{5}{|c|}{ Social support } \\
\hline High & 123092 & 80.66 & 112263 & 80.91 \\
\hline Low & 29508 & 19.34 & 26483 & 19.09 \\
\hline \multicolumn{5}{|c|}{ Tension related to the public } \\
\hline Low & 101987 & 66.83 & 86539 & 62.37 \\
\hline High & 50613 & 33.17 & 52207 & 37.63 \\
\hline \multicolumn{5}{|l|}{ Reward } \\
\hline High & 107981 & 70.76 & 94985 & 68.46 \\
\hline Low & 44619 & 29.24 & 43761 & 31.54 \\
\hline \multicolumn{5}{|c|}{ Work-life imbalance } \\
\hline Low & 114312 & 74.91 & 99693 & 71.85 \\
\hline High & 38288 & 25.09 & 39053 & 28.15 \\
\hline \multicolumn{5}{|c|}{$\begin{array}{l}\text { PSYCHOSOCIAL WORK FACTORS } \\
\text { (frequency variables) }\end{array}$} \\
\hline \multicolumn{5}{|c|}{ High psychological demands } \\
\hline Never & 74555 & 48.86 & 71844 & 51.78 \\
\hline Rarely & 37119 & 24.32 & 33269 & 23.98 \\
\hline Often & 21531 & 14.11 & 17342 & 12.50 \\
\hline Always & 19395 & 12.71 & 16291 & 11.74 \\
\hline \multicolumn{5}{|c|}{ Low skill discretion } \\
\hline Never & 103401 & 67.76 & 87985 & 63.41 \\
\hline Rarely & 29826 & 19.55 & 29366 & 21.17 \\
\hline Often & 12748 & 8.35 & 13602 & 9.80 \\
\hline Always & 103407 & 4.34 & 7793 & 5.62 \\
\hline \multicolumn{5}{|c|}{ Low social support } \\
\hline Never & 123092 & 80.66 & 112263 & 80.91 \\
\hline Rarely & 21234 & 13.91 & 18245 & 13.15 \\
\hline Often & 6595 & 4.32 & 6428 & 4.63 \\
\hline Always & 1679 & 1.10 & 1810 & 1.30 \\
\hline \multicolumn{5}{|c|}{ High tension related to the public } \\
\hline Never & 101987 & 66.83 & 86539 & 62.37 \\
\hline Rarely & 34296 & 22.47 & 35788 & 25.79 \\
\hline Often & 10440 & 6.84 & 10906 & 7.86 \\
\hline Always & 5877 & 3.85 & 5513 & 3.97 \\
\hline \multicolumn{5}{|c|}{ Low reward } \\
\hline Never & 71705 & 46.99 & 61442 & 44.28 \\
\hline Rarely & 36276 & 23.77 & 33543 & 24.18 \\
\hline Often & 27102 & 17.76 & 25651 & 18.49 \\
\hline Always & 17517 & 11.48 & 18110 & 13.05 \\
\hline \multicolumn{5}{|c|}{ Work-life imbalance } \\
\hline Never & 114312 & 74.91 & 99693 & 71.85 \\
\hline Rarely & 22008 & 14.42 & 22883 & 16.49 \\
\hline Often & 10410 & 6.82 & 10050 & 7.24 \\
\hline Always & 5870 & 3.85 & 6120 & 4.41 \\
\hline
\end{tabular}




\begin{tabular}{lcccc}
\hline $\begin{array}{l}\text { COVARIATES } \\
\text { Age (y) }\end{array}$ & & & & \\
$18-29$ & 54907 & 35.98 & 53831 & 38.80 \\
$30-39$ & 46147 & 30.24 & 39585 & 28.53 \\
$40-49$ & 33198 & 21.75 & 29428 & 21.21 \\
$50-64$ & 18348 & 12.02 & 15902 & 11.46 \\
Marital status & & & & \\
Alone & 38216 & 25.04 & 37594 & 27.10 \\
Not alone & 114384 & 74.96 & 101152 & 72.90 \\
Life events before 18 y & & & \\
0 & 66982 & 43.89 & 58817 & 42.39 \\
1 & 39388 & 25.81 & 34501 & 24.87 \\
2 or more & 46230 & 30.29 & 45428 & 32.74 \\
Life events during adulthood & & & & \\
0 & 114549 & 75.06 & 104064 & 75.00 \\
1 & 28129 & 18.43 & 23950 & 17.26 \\
2 or more & 9922 & 6.50 & 10732 & 7.73 \\
Occupation & & & & \\
Managers, professionals & 17446 & 11.43 & 12287 & 8.86 \\
Associate professionals, technicians & 30889 & 20.24 & 28704 & 20.69 \\
Clerks, service workers & 22467 & 14.72 & 70658 & 50.93 \\
Blue collar workers & 81798 & 53.60 & 27097 & 19.53 \\
\hline
\end{tabular}


Table 2 Associations between psychosocial work factors and first depressive episode: results from weighted discrete time logistic regression models with adjustment for covariates

\begin{tabular}{|c|c|c|c|c|}
\hline & $\begin{array}{l}\text { Men } \\
\text { OR }\end{array}$ & $\begin{array}{c}\mathrm{N}=152600 \\
\text { persons-years } \\
95 \% \mathrm{CI}\end{array}$ & Women & $\begin{array}{c}\mathrm{N}=138746 \\
\text { persons-years } \\
95 \% \mathrm{CI}\end{array}$ \\
\hline \multicolumn{5}{|l|}{ Each factor studied SEPARATELY } \\
\hline High psychological demands & $2.54 * * *$ & $1.70-3.79$ & $3.06 * * *$ & 2.37-3.95 \\
\hline Low skill discretion & 1.35 & $0.94-1.93$ & $1.33^{*}$ & $1.06-1.69$ \\
\hline Low social support & $2.42 * * *$ & 1.65-3.56 & $2.15 * * *$ & $1.68-2.76$ \\
\hline High tension related to the public & 1.34 & $0.92-1.97$ & $1.64 * * *$ & $1.28-2.10$ \\
\hline Low reward & $1.83 * * *$ & $1.28-2.63$ & $1.72 * * *$ & $1.36-2.17$ \\
\hline Work-life imbalance & $1.48 *$ & $1.02-2.14$ & $1.36 *$ & 1.06-1.75 \\
\hline \multicolumn{5}{|c|}{ All factors studied SIMULTANEOUSLY } \\
\hline High psychological demands & $2.08 * *$ & $1.33-3.23$ & $2.49 * * *$ & 1.89-3.27 \\
\hline Low skill discretion & 0.96 & $0.65-1.40$ & 1.00 & $0.78-1.29$ \\
\hline Low social support & $1.92^{* *}$ & $1.27-2.90$ & $1.59 * * *$ & $1.22-2.06$ \\
\hline High tension related to the public & 0.98 & $0.66-1.44$ & 1.19 & $0.92-1.54$ \\
\hline Low reward & 1.42 & $0.96-2.10$ & 1.25 & $0.97-1.61$ \\
\hline Work-life imbalance & 1.14 & $0.78-1.67$ & 1.03 & $0.79-1.32$ \\
\hline
\end{tabular}

Psychosocial work factors were defined using the median of the distribution among the total sample

Adjustment for age, marital status, life events before $18 \mathrm{y}$, life events during adulthood, and occupation

Bold: OR significant at $5 \%$

***: $\mathrm{p}<0.001,{ }^{* *}: \mathrm{p}<0.01,{ }^{*}: \mathrm{p}<0.05$ 
Table 3 Associations between the frequency of exposure to psychosocial work factors and first depressive episode: results from weighted discrete time logistic regression models with adjustment for covariates

\begin{tabular}{|c|c|c|c|c|c|c|}
\hline & Men & $\begin{array}{c}\mathrm{N}=152600 \\
\text { persons-years }\end{array}$ & $\begin{array}{l}\text { Trend } \\
\text { test }\end{array}$ & Women & $\begin{array}{c}\mathrm{N}=138746 \\
\text { persons-years }\end{array}$ & $\begin{array}{c}\text { Trend } \\
\text { test }\end{array}$ \\
\hline \multicolumn{7}{|l|}{ Each factor studied SEPARATELY } \\
\hline High psychological demands (ref never) & & & $* * *$ & & & $* * *$ \\
\hline Rarely & 1.44 & $0.87-2.37$ & & 2.02 & 1.45-2.81 & \\
\hline Often & 3.48 & 2.11-5.75 & & 3.76 & 2.69-5.26 & \\
\hline Always & 3.49 & 2.13-5.72 & & 4.47 & 3.29-6.09 & \\
\hline Low skill discretion (ref never) & & & $* *$ & & & $* * *$ \\
\hline Rarely & 1.01 & $0.63-1.60$ & & 0.98 & $0.72-1.32$ & \\
\hline Often & 1.57 & $0.89-2.77$ & & 1.76 & 1.24-2.51 & \\
\hline Always & 2.46 & 1.28-4.71 & & 2.04 & 1.33-3.12 & \\
\hline Low social support (ref never) & & & $* * *$ & & & $* * *$ \\
\hline Rarely & 1.70 & 1.08-2.67 & & 1.72 & 1.26-2.35 & \\
\hline Often & 4.83 & 2.84-8.20 & & 2.68 & 1.82-3.95 & \\
\hline Always & 1.97 & $0.66-5.88$ & & 4.58 & 2.77-7.57 & \\
\hline High tension related to the public (ref never) & & & $* *$ & & & $* * *$ \\
\hline Rarely & 0.94 & $0.59-1.50$ & & 1.17 & $0.87-1.56$ & \\
\hline Often & 2.41 & 1.45-4.00 & & 2.47 & 1.73-3.53 & \\
\hline Always & 1.57 & 0.81-3.02 & & 3.02 & 1.97-4.63 & \\
\hline Low reward (ref never) & & & $* * *$ & & & $* * *$ \\
\hline Rarely & 1.63 & $1.02-2.60$ & & 1.58 & 1.16-2.16 & \\
\hline Often & 1.88 & $1.20-2.94$ & & 2.07 & 1.51-2.84 & \\
\hline Always & 2.80 & 1.65-4.74 & & 2.06 & 1.46-2.89 & \\
\hline Work-life imbalance (ref never) & & & $* *$ & & & $*$ \\
\hline Rarely & 1.17 & $0.71-1.94$ & & 0.97 & $0.68-1.38$ & \\
\hline Often & 2.01 & 1.16-3.46 & & 1.84 & $1.30-2.60$ & \\
\hline Always & 1.60 & $0.82-3.14$ & & 1.94 & 1.21-3.12 & \\
\hline \multicolumn{7}{|l|}{ All factors studied SIMULTANEOUSLY } \\
\hline High psychological demands (ref never) & & & $* * *$ & & & $* * *$ \\
\hline Rarely & 1.32 & $0.80-2.19$ & & 1.84 & 1.30-2.61 & \\
\hline Often & 2.63 & 1.44-4.82 & & 2.98 & 2.11-4.21 & \\
\hline Always & 2.55 & 1.51-4.31 & & 3.10 & 2.19-4.40 & \\
\hline Low skill discretion (ref never) & & & ns & & & ns \\
\hline Rarely & 0.71 & $0.43-1.16$ & & 0.76 & $0.56-1.05$ & \\
\hline Often & 0.95 & $0.52-1.75$ & & 1.22 & $0.84-1.77$ & \\
\hline Always & 1.59 & $0.77-3.28$ & & 1.36 & $0.84-2.20$ & \\
\hline Low social support (ref never) & & & $* *$ & & & $* * *$ \\
\hline Rarely & 1.40 & $0.86-2.27$ & & 1.31 & $0.93-1.84$ & \\
\hline Often & 3.45 & 1.93-6.17 & & 1.81 & 1.23-2.64 & \\
\hline Always & 1.20 & $0.36-4.01$ & & 2.93 & 1.72-4.99 & \\
\hline High tension related to the public (ref never) & & & ns & & & $*$ \\
\hline Rarely & 0.76 & $0.48-1.22$ & & 0.95 & $0.70-1.29$ & \\
\hline Often & 1.43 & $0.82-2.52$ & & 1.47 & 1.01-2.16 & \\
\hline Always & 0.82 & $0.40-1.70$ & & 1.56 & $0.99-2.47$ & \\
\hline Low reward (ref never) & & & ns & & & ns \\
\hline Rarely & 1.41 & $0.86-2.32$ & & 1.35 & $0.97-1.88$ & \\
\hline Often & 1.35 & $0.82-2.23$ & & 1.35 & $0.95-1.94$ & \\
\hline Always & 1.60 & $0.87-2.93$ & & 1.00 & $0.68-1.48$ & \\
\hline Work-life imbalance (ref never) & & & $*$ & & & ns \\
\hline Rarely & 0.93 & $0.56-1.56$ & & 0.74 & $0.52-1.06$ & \\
\hline Often & 1.26 & $0.72-2.23$ & & 1.24 & $0.86-1.80$ & \\
\hline Always & 1.13 & $0.57-2.27$ & & 1.25 & $0.76-2.05$ & \\
\hline
\end{tabular}

Adjustment for age, marital status, life events before $18 \mathrm{y}$, life events during adulthood, and occupation

Bold: OR significant at $5 \%$

***: $\mathrm{p}<0.001, * *: \mathrm{p}<0.01, *$ : $\mathrm{p}<0.05$ 
Table 4 Associations between the number of years exposed to psychosocial work factors (continuous variables) and first depressive episode: results from weighted discrete time logistic regression models with adjustment for covariates

\begin{tabular}{|c|c|c|c|c|}
\hline & $\begin{array}{l}\text { Men } \\
\text { OR }\end{array}$ & $\begin{array}{c}\mathrm{N}=158100 \\
\text { persons-years } \\
95 \% \mathrm{CI}\end{array}$ & $\begin{array}{c}\text { Women } \\
\text { OR }\end{array}$ & $\begin{array}{c}\mathrm{N}=162849 \\
\text { persons-years } \\
95 \% \mathrm{CI}\end{array}$ \\
\hline \multicolumn{5}{|l|}{ Each factor studied SEPARATELY } \\
\hline High psychological demands & $1.03 * * *$ & 1.02-1.05 & $1.05 * * *$ & 1.03-1.06 \\
\hline Low skill discretion & 1.01 & $0.99-1.02$ & 1.01 & $1.00-1.02$ \\
\hline Low social support & $1.04 * * *$ & 1.03-1.06 & $1.03 * * *$ & 1.02-1.04 \\
\hline High tension related to the public & $1.03 * *$ & 1.01-1.04 & $1.02 *$ & 1.00-1.03 \\
\hline Low reward & $1.02 * *$ & 1.01-1.04 & $1.02 * * *$ & 1.01-1.04 \\
\hline Work-life imbalance & $1.02 *$ & 1.00-1.04 & $1.02 * *$ & 1.01-1.03 \\
\hline \multicolumn{5}{|c|}{ All factors studied SIMULTANEOUSLY } \\
\hline High psychological demands & $1.02 *$ & $1.00-1.04$ & $1.04 * * *$ & 1.03-1.06 \\
\hline Low skill discretion & 0.99 & $0.97-1.01$ & 1.00 & $0.98-1.01$ \\
\hline Low social support & $1.03 * * *$ & 1.02-1.05 & $1.02 *$ & 1.00-1.03 \\
\hline High tension related to the public & 1.01 & $0.99-1.03$ & 1.00 & $0.99-1.02$ \\
\hline Low reward & 1.01 & $1.00-1.03$ & 1.01 & $1.00-1.03$ \\
\hline Work-life imbalance & 1.01 & 0.99-1.02 & 1.00 & 0.99-1.02 \\
\hline
\end{tabular}

Adjustment for age, marital status, life events before $18 \mathrm{y}$, life events during adulthood, occupation, number of years unemployed or non-working

OR: increase in risk of first depressive episode associated with one year of exposure in excess

Bold: OR significant at $5 \%$

$* * *: \mathrm{p}<0.001, * *: \mathrm{p}<0.01, *: \mathrm{p}<0.05$ 
Table 5 Associations between the time of last exposure to psychosocial work factors and first depressive episode: results from weighted discrete time logistic regression models with adjustment for covariates

\begin{tabular}{|c|c|c|c|c|c|c|}
\hline & \multicolumn{3}{|c|}{ Men $(\mathrm{N}=141941)$} & \multicolumn{3}{|c|}{ Women $(\mathrm{N}=123452)$} \\
\hline & OR & $95 \%$ CI & $\mathrm{p}$ & OR & $95 \% \mathrm{CI}$ & $\mathrm{p}$ \\
\hline \multicolumn{7}{|l|}{ Each factor studied SEPARATELY } \\
\hline High psychological demands & & & $* * *$ & & & $* * *$ \\
\hline Non-exposed in i, i-1 and i-2 & 1 & & & 1 & & \\
\hline Non-exposed in i but exposed in $\mathrm{i}-1$ or $\mathrm{i}-2$ & 1.74 & $0.53-5.78$ & & 0.53 & $0.13-2.21$ & \\
\hline Exposed in i & 2.72 & $1.77-4.19$ & & 3.00 & 2.28-3.94 & \\
\hline Low skill discretion & & & ns & & & ns \\
\hline Non-exposed in i, i-1 and i-2 & 1 & & & 1 & & \\
\hline Non-exposed in i but exposed in $\mathrm{i}-1$ or $\mathrm{i}-2$ & 2.33 & $0.64-8.51$ & & 0.66 & $0.25-1.75$ & \\
\hline Exposed in $\mathrm{i}$ & 1.32 & $0.91-1.93$ & & 1.29 & 1.01-1.65 & \\
\hline Low social support & & & $* * *$ & & & $* * *$ \\
\hline Non-exposed in i, i-1 and i-2 & 1 & & & 1 & & \\
\hline Non-exposed in i but exposed in $\mathrm{i}-1$ or $\mathrm{i}-2$ & 2.12 & $0.76-5.90$ & & 1.82 & $0.60-5.52$ & \\
\hline Exposed in i & 2.55 & $1.70-3.81$ & & 2.10 & $1.62-2.73$ & \\
\hline High tension related to the public & & & ns & & & $* * *$ \\
\hline Non-exposed in i, i-1 and i-2 & 1 & & & & & \\
\hline Non-exposed in i but exposed in $\mathrm{i}-1$ or $\mathrm{i}-2$ & 0.77 & $0.23-2.56$ & & 1.47 & $0.40-5.36$ & \\
\hline Exposed in i & 1.44 & $0.97-2.15$ & & 1.71 & $1.32-2.21$ & \\
\hline Low reward & & & $* *$ & & & $* * *$ \\
\hline Non-exposed in i, i-1 and i-2 & 1 & & & 1 & & \\
\hline Non-exposed in i but exposed in $\mathrm{i}-1$ or $\mathrm{i}-2$ & 2.81 & $0.73-10.8$ & & 1.41 & $0.64-3.11$ & \\
\hline Exposed in i & 1.90 & $1.30-2.78$ & & 1.83 & 1.43-2.34 & \\
\hline Work-life imbalance & & & ns & & & ns \\
\hline Non-exposed in i, i-1 and i-2 & 1 & & & 1 & & \\
\hline Non-exposed in i but exposed in $\mathrm{i}-1$ or $\mathrm{i}-2$ & 0.80 & $0.19-3.29$ & & 1.67 & $0.64-4.31$ & \\
\hline Exposed in i & 1.45 & $0.98-2.14$ & & 1.26 & $0.97-1.64$ & \\
\hline \multicolumn{7}{|l|}{ All factors studied SIMULTANEOUSLY } \\
\hline High psychological demands & & & $* *$ & & & $* * *$ \\
\hline Non-exposed in i, i-1 and i-2 & 1 & & & 1 & & \\
\hline Non-exposed in i but exposed in $\mathrm{i}-1$ or $\mathrm{i}-2$ & 1.42 & $0.40-4.95$ & & 0.42 & $0.09-1.90$ & \\
\hline Exposed in i & 2.19 & $1.38-3.47$ & & 2.43 & 1.83-3.23 & \\
\hline Low skill discretion & & & ns & & & ns \\
\hline Non-exposed in i, i-1 and i-2 & 1 & & & 1 & & \\
\hline Non-exposed in i but exposed in $\mathrm{i}-1$ or $\mathrm{i}-2$ & 1.59 & $0.46-5.51$ & & 0.48 & $0.16-1.44$ & \\
\hline Exposed in $\mathrm{i}$ & 0.90 & $0.60-1.34$ & & 0.94 & $0.72-1.22$ & \\
\hline Low social support & & & $* *$ & & & $* *$ \\
\hline Non-exposed in i, i-1 and i-2 & 1 & & & 1 & & \\
\hline Non-exposed in i but exposed in $\mathrm{i}-1$ or $\mathrm{i}-2$ & 1.47 & $0.40-5.41$ & & 1.81 & $0.58-5.61$ & \\
\hline Exposed in i & 2.01 & $1.29-3.13$ & & 1.54 & 1.17-2.04 & \\
\hline High tension related to the public & & & ns & & & ns \\
\hline Non-exposed in i, i-1 and i-2 & 1 & & & 1 & & \\
\hline Non-exposed in i but exposed in $\mathrm{i}-1$ or $\mathrm{i}-2$ & 0.55 & $0.16-1.92$ & & 1.21 & $0.29-5.02$ & \\
\hline Exposed in $\mathrm{i}$ & 1.02 & $0.68-1.55$ & & 1.25 & $0.95-1.63$ & \\
\hline Low reward & & & ns & & & ns \\
\hline Non-exposed in i, i-1 and i-2 & 1 & & & 1 & & \\
\hline Non-exposed in i but exposed in $\mathrm{i}-1$ or $\mathrm{i}-2$ & 2.14 & $0.55-8.32$ & & 1.38 & $0.54-3.49$ & \\
\hline Exposed in i & 1.46 & $0.96-2.22$ & & 1.37 & 1.05-1.78 & \\
\hline Work-life imbalance & & & ns & & & ns \\
\hline Non-exposed in i, i-1 and i-2 & 1 & & & 1 & & \\
\hline Non-exposed in i but exposed in $\mathrm{i}-1$ or $\mathrm{i}-2$ & 0.58 & $0.14-2.41$ & & 1.49 & $0.57-3.89$ & \\
\hline Exposed in i & 1.07 & $0.71-1.60$ & & 0.93 & $0.71-1.21$ & \\
\hline
\end{tabular}

